\title{
O gênero Garapita Oman (Hemiptera, Cicadellidae, Deltocephalinae) com descrições de quatro novas espécies 1
}

\author{
Keti Maria Rocha Zanol ${ }^{2}$ \\ 1 Contribuição número 1400 do Departamento de Zoologia, Universidade Federal do Paraná. \\ 2 Departamento de Zoologia, Universidade Federal do Paraná. Caixa Postal 19020, 81531-980 Curitiba, Paraná, Brasil. \\ Bolsista do CNPq.
}

\begin{abstract}
The genus Garapita Oman (Hemiptera, Cicadellidae, Deltocephalinae) with descriptions of four new species. Garapita Oman is redescribed and four new species are described, G. (G.) guajarensis sp. nov., G. (G.) sinopia sp. nov., G. (G.) computa sp. nov., from Brazil and $G$. (G.) paraguaiensis sp. nov. from Paraguay. A new combination is established, G. (G.) clitellaria (Osborn, 1923), comb. nov. and G. (G.) pulchripennis Linnavuori, 1959 is considered a new synonym. The male of G. (G.) clitellaria, up to now unknown, is described. G. (G.) garbosa Oman, 1936 is reported for the first time in Brazil; G. (Chlamydopita) aurea Linnavuori, 1959 is redescribed and illustrated.
\end{abstract}

KEY WORDS. Cicadellidae, Deltocephalinae, Garapita, Hemiptera, taxonomy.

O gênero Garapita foi estabelecido por OMAN (1936), designando Garapita garbosa Oman, 1936 como espécie-tipo (Argentina). LinNAVuori (1959) subdividiu o gênero em dois subgêneros: Garapita (Garapita) e Garapita (Chlamydopita); no primeiro incluiu G. pulchripennis Linnavuori, 1959 e no segundo G. áurea Linnavuori, 1959, ambas do Brasil.

O material estudado pertence às seguintes Instituições: Coleção de Entomologia Pe J.S. Moure, Departamento de Zoologia, Universidade Federal do Paraná, Curitiba, Paraná (DZUP), Instituto Nacional de Pesquisas da Amazônia, Manaus, Amazonas (INPA), Ministerio de Agricultura y Ganaderia, Inventario Biológico Nacional, Assunção, Paraguai (IBNP), American Museum of Natural History, Nova Iorque, USA (AMNH).

No item material examinado, são apresentados os dados contidos nas etiquetas; as localidades/distribuição precedidas de asterisco $\left({ }^{*}\right)$ representam um novo registro. As medidas são fornecidas em milímetros

\section{Garapita Oman, 1936}

Garapita Oman, 1936: 369 (descrição). Espécie-tipo: Garapita garbosa (designação original); Linnavuori, 1959: 222 (redescrição); Evans, 1947: 243 (citação); Metcalf, 1967: 2104 (catálogo); Zanol \& Menezes, 1982: 40 (citação).

Cabeça, em vista dorsal, ligeiramente mais larga do que o pronoto. Coroa mais longa medianamente do que junto aos olhos; região frontal microesculturada e a discal lisa; ocelos, na margem anterior, visíveis de cima, perto dos olhos; sutura coronal atingindo a metade do comprimento da coroa. Frontoclípeo intumescido. Genas com as margens sinuosas, abaixo dos olhos. Anteclípeo intumescido, de lados paralelos e ápice arredondado.

Tégminas semitransparentes; com duas células anteapicais fechadas; célula anteapical externa frequentemente triangular mais curta que a célula anteapical central; apêndice desenvolvido. Espinulação das tíbias anteriores $1+4$ e dos fêmures posteriores $2+2+1$.

Pigóforo com ápice arredondado. Valva genital triangular. Placas subgenitais triangulares com poucas macrocerdas; distalmente afilada, pouco esclerotinizada e rugosa. Conetivo com os braços divergentes. Edeago simétrico com apêndices basais. Gonóporo subapical, na superfície ventral.

Tamanho. Macho: 3,90-5,10. Fêmea: 4,40-5,80.

Distribuição: Brasil, *Paraguai, Argentina.

\section{Garapita (Garapita) Oman, 1936}

Garapita Oman, 1936: 369-370. Espécie-tipo, Garapita garbosa Oman, 1936: 370.

Garapita (Garapita); Linnavuori, 1959: 223.

Coloração marrom com manchas amarelas. Tégminas geralmente com uma veia extranumerária entre 1A e a sutura claval; célula anteapical externa triangular; margem costal com áreas tranparentes. Pigóforo, do macho, com ou sem apêndices. Estilos com apófise alongada; ângulo pré-apical distinto. 


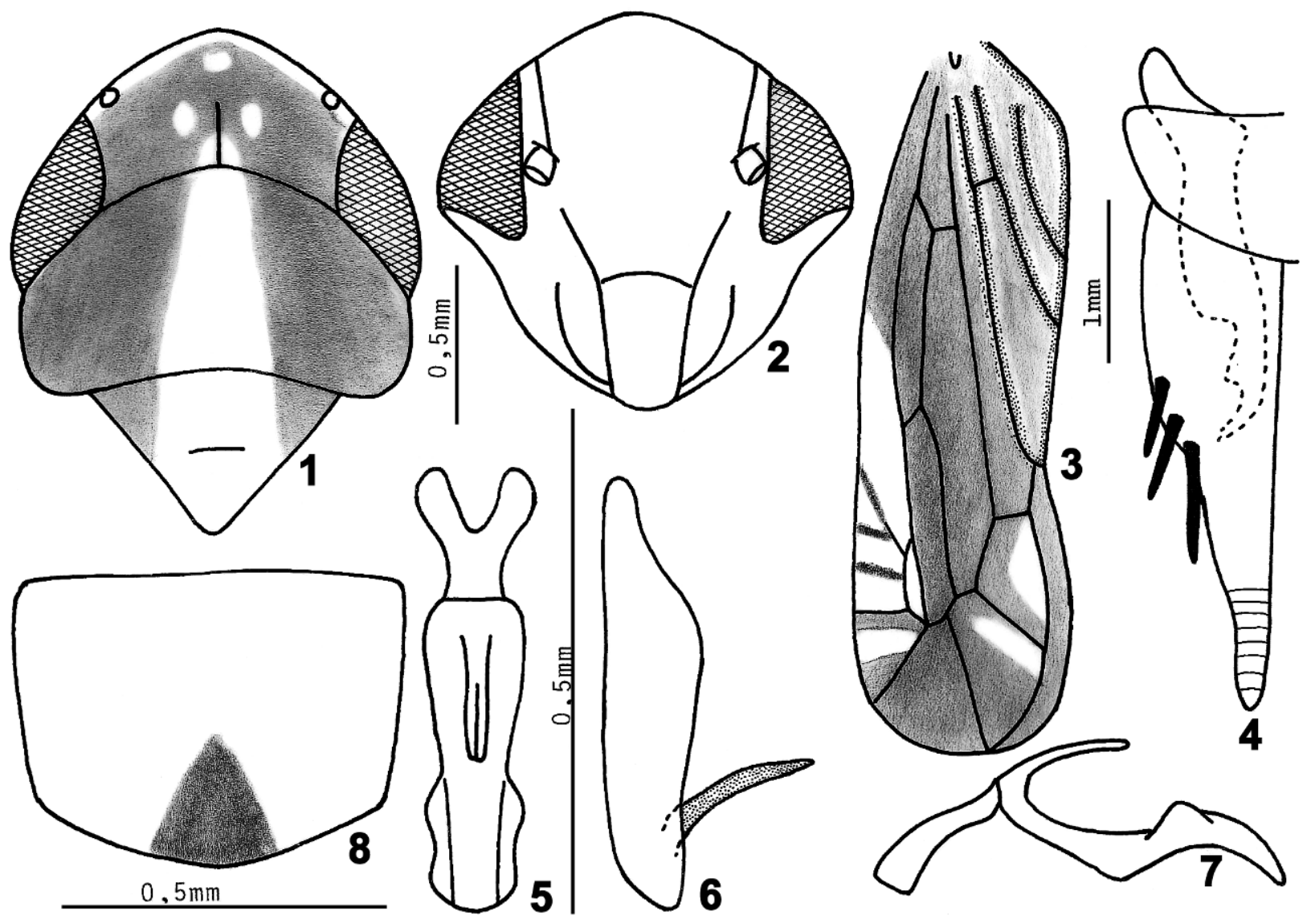

Figs 1-8. Garapita (G.) garbosa Oman, 1936. (1) cabeça, pronoto e escutelo; (2) face; (3) tégmina; (4) valva genital, placa subgenital e estilo; (5) conetivo e edeago, ventral; (6) pigóforo, lateral; (7) conetivo e edeago, lateral; (8) sétimo esterno da fêmea.

\section{Garapita (Garapita) garbosa Oman, 1936 Figs 1-8}

Garapita garbosa Oman, 1936: 370 (descrição). Evans, 1947: 243 (citação); Metcalf, 1967: 2104 (catalogo).

Garapita (Garapita) garbosa; Linnavuori, 1959: 223-224 (redescrição).

Macho. Coroa marrom-escura margeada anteriormente por uma estreita faixa e com três manchas arredondadas, duas laterais a sutura coronal e uma à frente desta, e uma pequena mancha triangular, mediana, na margem posterior, amarelas. Face amarela.

Pronoto marrom-escuro com uma mancha longitudinal amarela, mais ou menos triangular, mediana. Escutelo amarelo; triângulos basais marrom-escuros.

Tégminas marrom-escuras; margem anal, ao longo das veias anais e da sutura claval, amarelas; margem costal, primeira e segunda células apicais, célula anteapical externa com áreas transparentes. Clavo com uma veia extranumerária entre $1 \mathrm{~A} \mathrm{e}$ a sutura claval. Célula anteapical externa triangular.

Pigóforo com um par de apêndices falciformes apicais, voltados para dentro. Estilos com apófise bífida. Edeago, em vista lateral, sinuoso; em vista ventral achatado; apêndices fundidos na metade basal, não alcançando a metade do comprimento do edeago.

Fêmea. Externamente semelhante ao macho. Sétimo esterno levemente projetado medianamente, com leve carena mediana no terço posterior.

Comprimento. Macho: 4,00-4,20. Fêmea: 4,60-5,00.

Material examinado. *BRASIL, Paraná: Telemaco Borba (Res. Samuel Klabin), 2.XI. 1987, Lev. Ent. PROFAUPAR, 1 macho; Ibidem, 2.XII.1986, 1 macho, 3 fêmeas; Ibidem, 4.XI.1986, 1 macho; Ibidem, 20.I.1988, 3 machos, 2 fêmeas; Ibidem, 30.XI.1986, 1 macho, 1 fêmea; Castro, 2.II. 1984, S. Malkowski leg., 1 fêmea; Guarapuava, (Est. Águas Sta Clara), 20.XI.1987, Lev. Ent. PROFAUPAR, 4 machos, 1 fêmea; Ibidem, 5.VIII. 1986, 1 fêmea; Ibidem, 17.I.1988, 1 fêmea; Ibidem, 29.XI. 1986, 1 macho. Santa Catarina: Caçador, II. 1984, A. Orth leg., 1 fêmea (DZUP).

Variação intraespecífica. As manchas arredondadas da coroa podem estar ausentes. Os apêndices do pigóforo podem apresentar um processo espiniforme na base. 


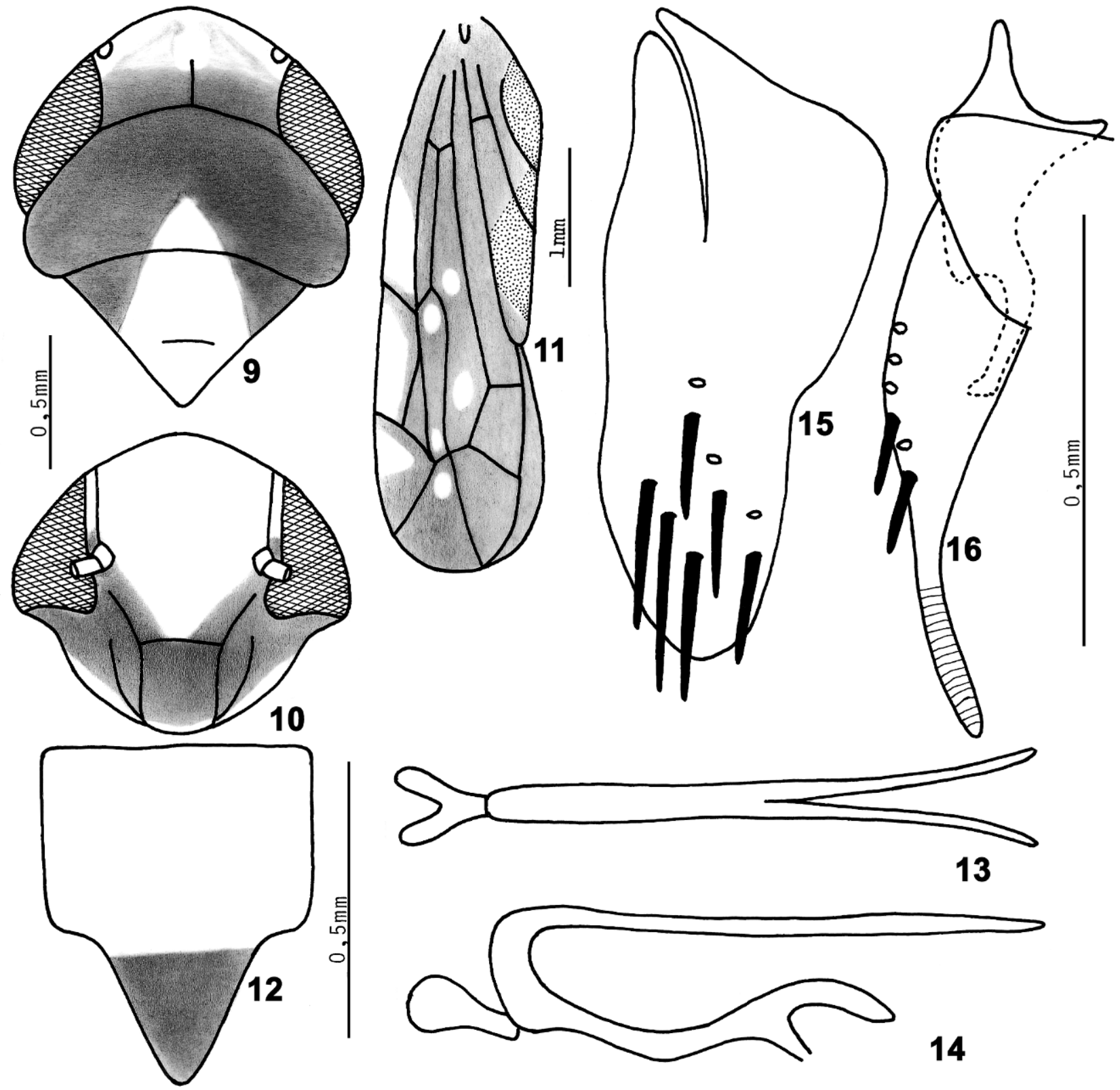

Figs 9-16. Garapita (G.) clitellaria (Osborn, 1923). (9) cabeça, pronoto e escutelo; (10) face; (11) tégmina; (12) sétimo esterno da fêmea; (13) conetivo e apêndices do edeago; (14) conetivo e edeago, lateral; (15) pigóforo, lateral; (16) valva genital, placa subgenital e estilo.

Garapita (Garapita) clitellaria comb. nov. Figs 9-16

Cicadella clitellaria Osborn, 1923: 185.

Garapita (Garapita) pulchripennis Linnavuori, 1959: 224-225 syn. nov.
Fêmea. Coroa marrom-escura; região frontal amarela. Face amarela com uma mancha marrom-escurea em forma de $\mathrm{V}$ que se estende desde os alvéolos antenais até próximo das margens.

Pronoto marrom-escuro com uma mancha triangular amarela na margem posterior. Escutelo amarelo; triângulos basais marrom-escuros. 


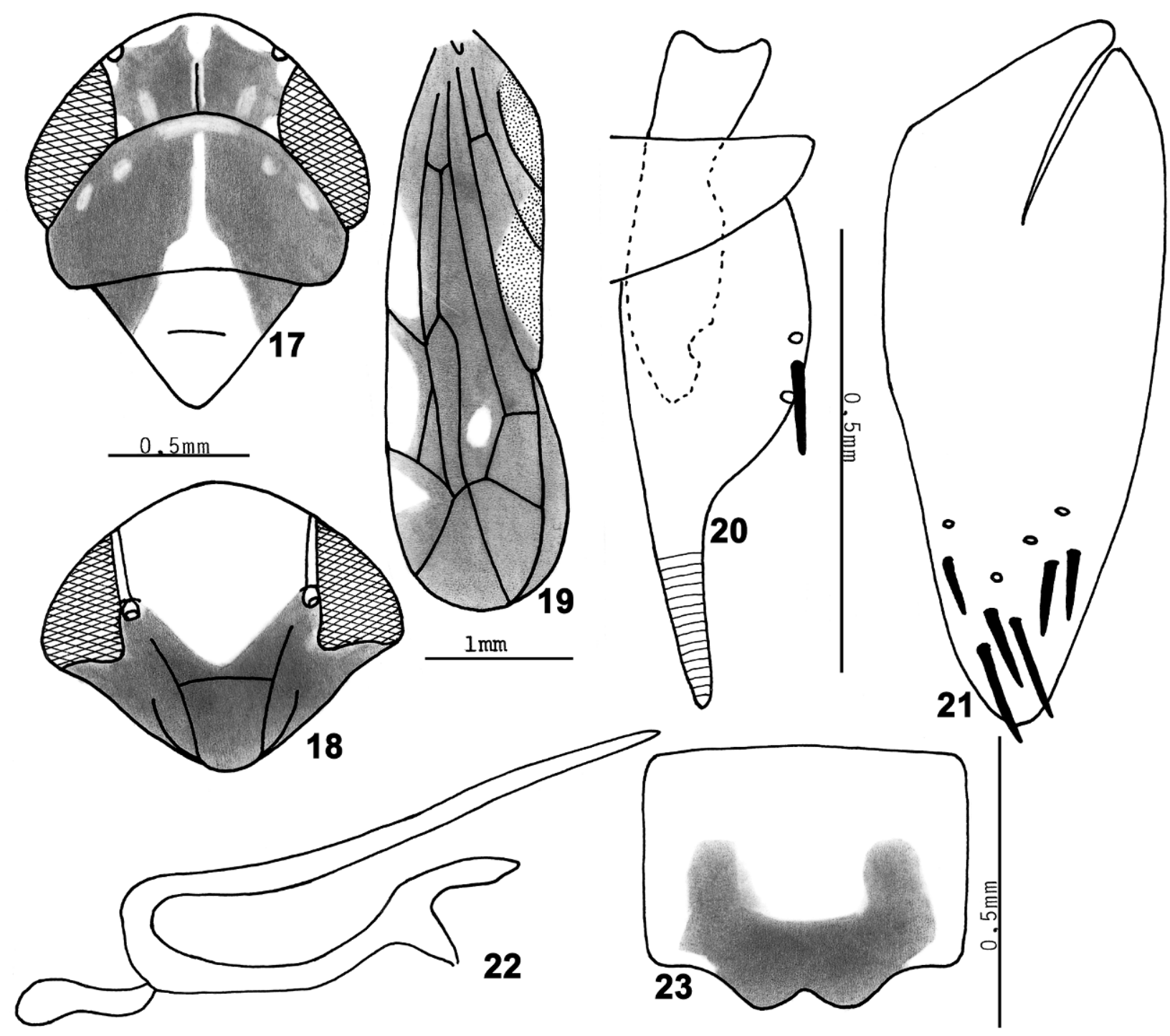

Figs 17-23. Garapita (G.) guajarensis sp. nov. (17) cabeça, pronoto e escutelo; (18) face; (19) tégmina; (20) valva genital, placa subgenital e estilo; (21) pigóforo lateral; (22) conetivo e edeago, lateral; (23) sétimo esterno da fêmea.

Tégminas marrom-escuras; margem costal transparente; clavo com uma grande mancha amarela, na margem anal. Clavo com uma veia extranumerária entre 1 A e sutura claval. Célula anteapical externa triangular.

Sétimo esterno mais ou menos quadrangular na base, projetada distalmente em um triângulo equilátero.

Macho. Externamente semelhante à fêmea. Pigóforo sem apêndices. Estilos digitiformes; ápice truncado. Edeago tubular, curvo para cima; apêndices sinuosos e divergentes, mais longos do que o edeago, fundidos na metade basal.

Comprimento. Macho: 4,20-4,50. Fêmea: 4,60-5,00.

Material examinado. Brasil, *Mato Grosso: Cáceres,
13.XI.1984, C. Elias leg. 8 machos. *Paraná: Foz do Iguaçu, 7.XII.66, D.Zoo, UFP leg., 1 macho; Fenix (Res. Estadual ITCF), 31.III.1987, Lev. Ent. PROFAUPAR, 2 machos, 1 fêmea; Ibidem, 20.III.1987, 1 macho, 2 fêmeas, Telemaco Borba (Res. Samuel Klabin), 2. XII.1986, Lev. Ent. PROFAUPAR, 2 machos, 4 fêmeas; Jundiaí do Sul (Fazenda Ouro Verde), 1;I.1987, 1 macho; Ibidem, 30.XI.1986, 2 fêmeas; Guarapuava (Est. Águas Sta Clara), 1.I.1987, Lev. Ent. PROFAUPAR, 1 macho, 1 fêmea; Ibidem, 29.XI.1986, 3 fêmeas; Ibidem, 29.IV.1987, 1 macho; Perobal, VIII. 1996, A. Kumagai leg., 1 fêmea; Engenheiro Beltrão, 26.XII.1986, J. A. Rafael leg., 1 fêmea; Morretes (IAPAR), 1.VIII.1984, CIIF leg., 5 fêmeas; Antonina (Res. Sapitanduva), 


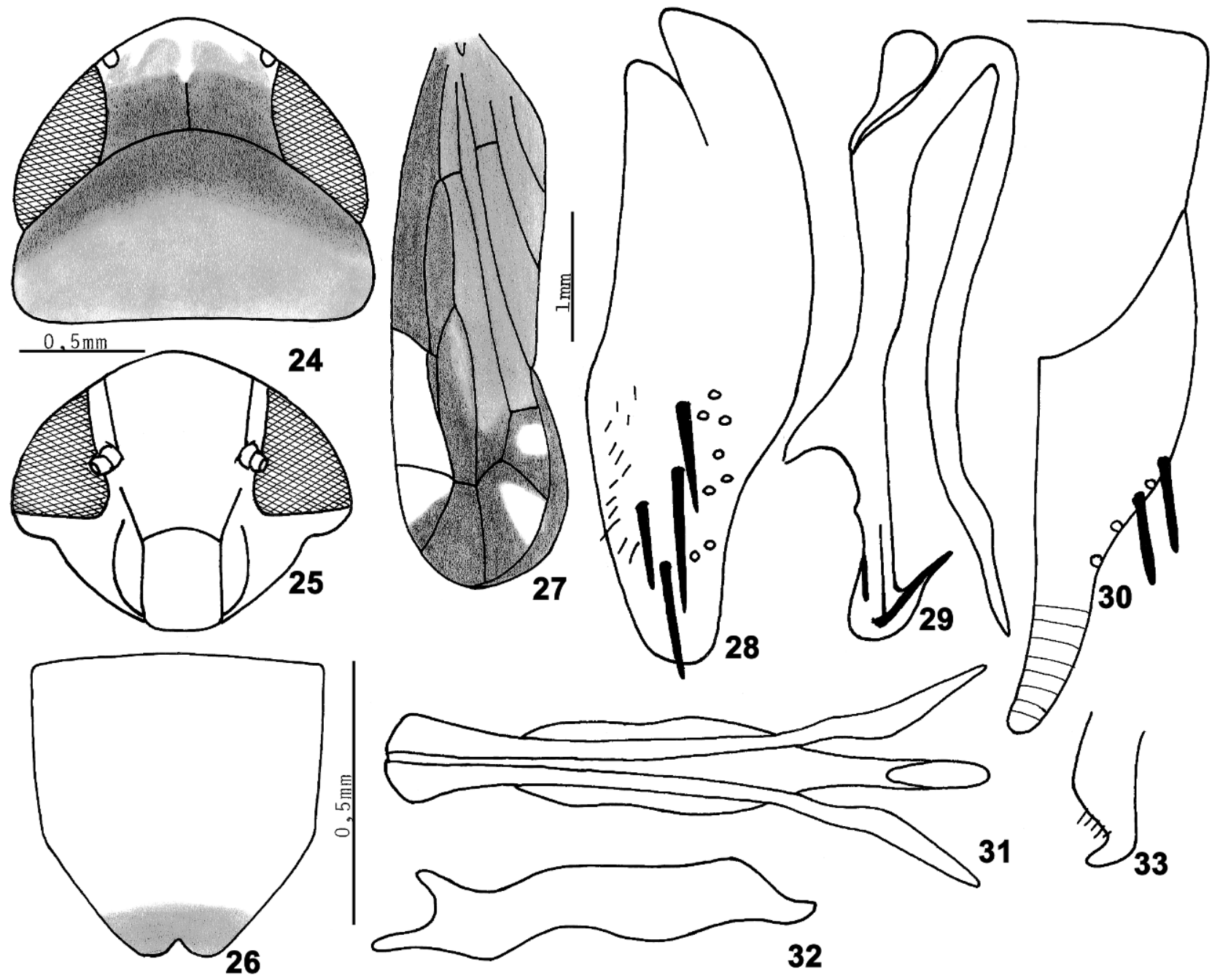

Figs 24-33. Garapita (G.) sinopia sp. nov. (24) cabeça e pronoto; (25) face; (26) sétimo esterno da fêmea; (27) tégmina; (28) pigóforo lateral; (29) conetivo e edeago, lateral; (30) valva genital e plava subgenital; (31) edeago, ventral; (32) estilo; (33) ápice do estilo, lateral.

4.XI.1986, Lev. Ent. PROFAUPAR, 1 fêmea; Ibidem, 2.I.1987, 1 fêmea; Colombo (Embrapa BR476 Km 20), 27.II.1987, Lev. Ent. PROFAUPAR, 1fêmea. (DZUP). *ParaguaI, Canindeyu: Reserva Natural del Bosque Mbaracayu, Jejui-mi, 29.V-11.VI.1996, 1 macho, A.C.F. Costa leg. (IBNP).

Comentário. Young (1977: 1106) na revisão da tribo Cicadellini (Cicadellinae) disse que Cicadella clitellaria Osborn, 1926 era uma espécie de Deltocephalinae sem indicar porém a qual gênero pertencia. Espécimes de $C$. clitellaria identificados por Young e depositados no Natural History Museum (BMNH) são idênticos com os espécimes identificados como Garapita pulchripennis Linnavuori (comunicação pessoal de M. Webb). Ambas as descrições, ou seja, de C. clitellaria e de G. pulchripennis foram baseadas em exemplares fêmeas, e, através destas e das ilustrações, achou-se por bem considerá-las como sinônimos.

\section{Garapita (Garapita) guajarensis sp. nov. Figs $17-23$}

Holótipo macho. Coroa marrom-escura; região frontal e uma faixa sobre a sutura coronal amarelas; região discal com áreas marrom-claras. Face amarela com uma mancha marromescura, em forma de $\mathrm{V}$ que se estende desde os alvéolos antenais até as margens.

Pronoto marrom, com uma mancha amarela, mais ou menos triangular, longitudinal e mediana. Escutelo amarelo; triângulos basais marrons.

Tégminas marrom-escuras; margem costal transparente;

Revista Brasileira de Zoologia 20 (2): 239-246, junho 2003 


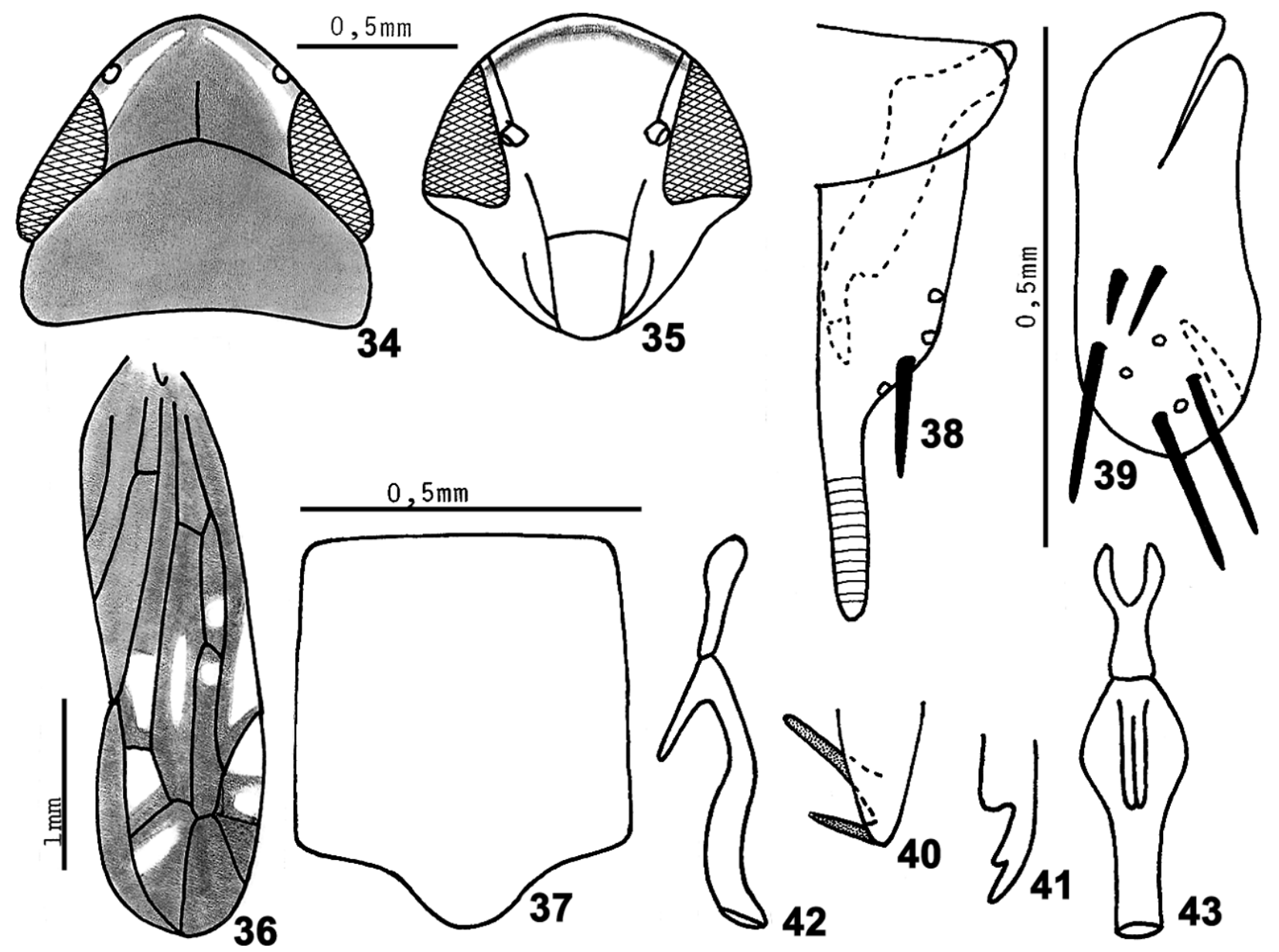

Figs 34-43. Garapita (G.) paraguaiensis sp. nov. (34) cabeça e pronoto; (35) face; (36) tégmina; (37) sétimo esterno da fêmea; (38) valva genital, placa subgenital e estilo; (39) pigóforo, lateral; (40) apêndices do pigóforo; (41) ápice do estilo; (42) conetivo e edeago, lateral; (43) conetivo e edeago, ventral.

clavo com uma grande mancha amarela, na margem anal;. Clavo com uma veia extranumerária entre a $1 \mathrm{~A}$ e a sutura claval. Célula anteapical externa triangular.

Pigóforo sem apêndices. Estilos com apófise curta e sem forma definida; ápice truncado. Edeago tubular, voltado para frente; apêndices sinuosos, divergentes, mais longos que o edeago, fundidos na metade basal.

Fêmea. Externamente semelhante ao macho. Sétimo esterno com margem posterior sinuosa e uma reentrância, no meio.

Comprimento. Macho. 4,20. Fêmea. 4,80.

Material examinado. Holótipo macho. Brasil, Rondônia: Nova Mamoré, Parque Estadual de Guajará-mirim, Rio Formoso (10¹9'26"S 64³3'88"W); 20-27.X.1995, J. Vidal \& L. S. Aquino leg. (17472-INPA). Parátipo. BRASIL, Amazonas: Guajará (Rio Ipixuna) (76'39"S 735'25"W) (32796-INPA).

Discussão. Semelhante a G. clitellaria (Osborn) no padrão de coloração da face, escutelo e tégminas. O edeago, em ambas, é tubular; os apêndices são fundidos na metade basal e mais longos que o edeago.

Revista Brasileira de Zoologia 20 (2): 239-246, junho 2003

\section{Garapita (Garapita) sinopia sp. nov.}

Figs 24-33

Holótipo macho. Coroa marrom-escura; região frontal amarela. Face amarela.

Pronoto marrom; margem anterior marrom-escura. Escutelo marrom.

Tégminas marrons; margem costal, primeira e segunda células apicais com áreas transparentes. Clavo com uma veia extranumerária entre $1 \mathrm{~A}$ e a sutura claval. Célula anteapical externa triangular.

Pigóforo sem apêndices. Estilos, em vista lateral, levemente falciformes; em vista ventral sem forma definida. Edeago mais ou menos reto com um processo ventro-apical, voltado para cima; apêndices basais sinuosos, divergentes, tão longos quanto o edeago.

Fêmea. Externamente semelhante ao macho. Sétimo esterno com as margens laterais convergentes distalmente; margem posterior com uma reentrância, em forma de $\mathrm{V}$ invertido, no meio. 


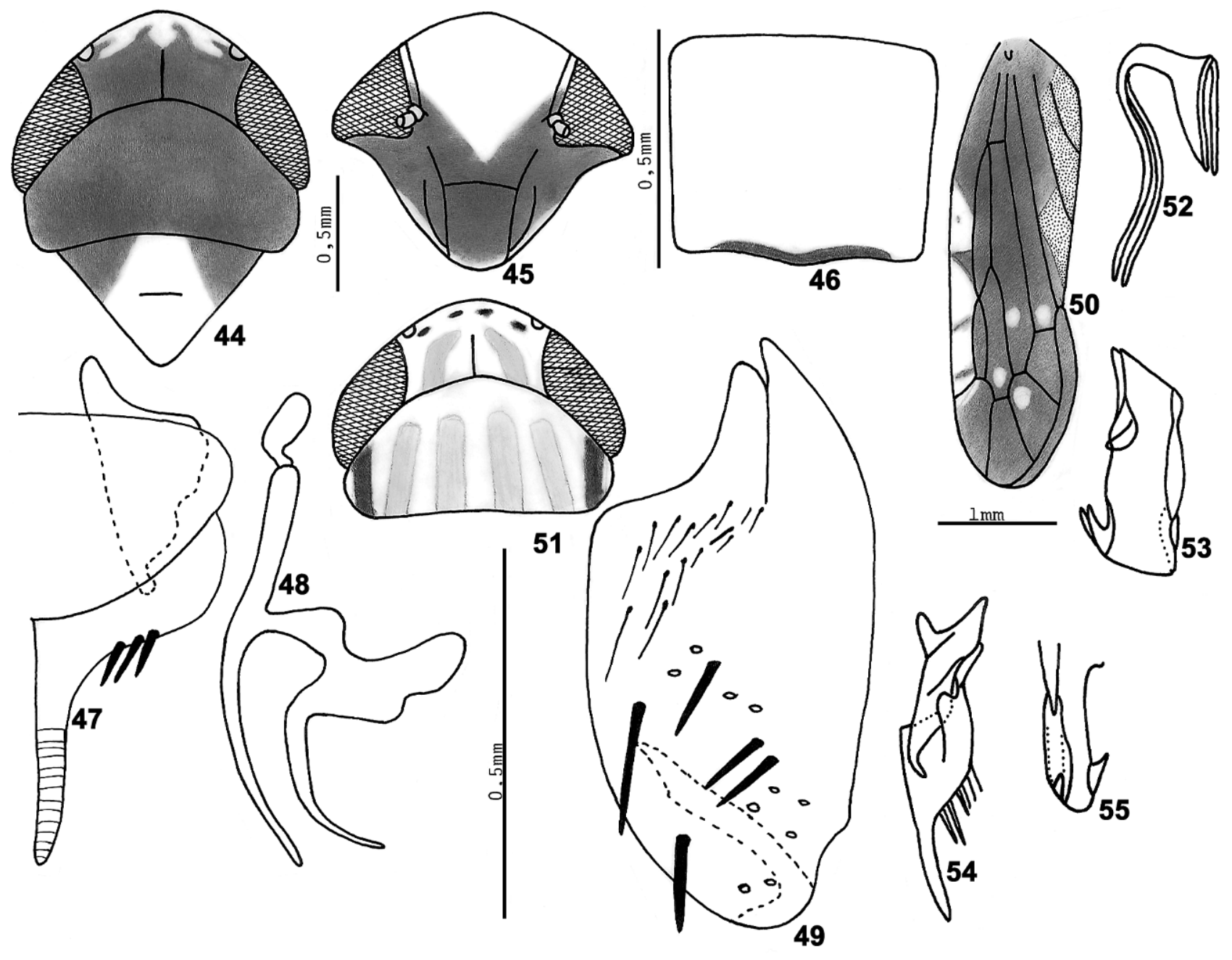

Figs 44-55. (44-50) Garapita (G.) computa sp. nov. (44) cabeça, pronoto e escutelo; (45) face; (46) sétimo esterno da fêmea; (47) valva genital, placa subgenital e estilo; (48) conetivo e edeago, lateral; (49) pigóforo, lateral; (50) tégmina. (51-55) Garapita (C.) aurea Linnavuori (51) cabeça e pronoto (holótipo); (52) apêndices do edeago; (53) edeago, lateral; (54) estilo e placa subgenital; (55) ápice do edeago (da literatura).

Comprimento. Macho: 4,80-5,10. Fêmea: 5,50-5,80.

Material examinado. Holótipo macho. BRASIL, Mato Grosso: Sinop, X.1975, M. Alvarenga leg. (DZUP). Parátipos. Com os mesmos dados do holótipo, 3 machos, 6 fêmeas (DZUP).

Discussão. Difere das demais espécies pelos processos apicais do edeago e pelos apêndices basais não serem fundidos.

\section{Garapita (Garapita) paraguaiensis sp. nov.} Figs 34-43

Holótipo macho. Coroa marrom-escura com uma faixa amarela, em forma de arco interrompida no meio; margem anterior amarela. Face amarela com uma estreita faixa marromescura acompanhando a curvatura da cabeça.
Pronoto e escutelo marrom-escuros.

Tégminas marrons; margem costal, primeira e segunda células apicais, célula discal e célula braquial com áreas transparentes. Clavo com uma veia extranumerária entre $1 \mathrm{~A} \mathrm{e}$ a sutura claval.

Pigóforo com dois pares de apêndices: o par apical, menor e voltado para dentro e um par subapical, maior, voltado para trás. Estilos em vista ventral digitiformes; em vista lateral, com apófise bífida. Edeago tubular, em vista lateral, sinuoso; metade basal, em vista ventral, mais larga; apêndices paralelos, atingindo a metade do comprimento do edeago, fundidos na base.

Fêmea. Externamente semelhante ao macho. Sétimo esterno com a margem posterior projetada num lobo mediano.

Revista Brasileira de Zoologia 20 (2): 239-246, junho 2003 
Comprimento. Macho: 3,90-4,10. Fêmea: 4,40-4,60.

Material examinado. Holótipo macho. Paragual, Canindeyú, Reserva Natural del Bosque Mbaracayú, Jjui-mi 26.VII8.VIII.1996, A.C.F. Costa leg.(DZUP). Parátipos.Com os mesmos dados do holótipo, 4 machos, 6 fêmeas (DZUP, IBNP).

Discussão. Aparentemente próxima a G. garbosa Oman por apresentar os estilos com apófise bífida e os apêndices basais do edeago curtos e fundidos na base.

\section{Garapita (Garapita) computa sp. nov. Figs 44-50}

Holótipo macho. Coroa marrom-escura; região frontal amarela. Face amarela com uma mancha marrom-escura, em forma de $\mathrm{V}$ que se estende desde os alvéolos antenais até próximo às margens.

Pronoto marrom-escuro. Escutelo amarelo com triângulos basais marrom-escuros.

Tégminas marrom-escuras; margem costal transparente; clavo com uma grande mancha amarela, na margem anal. Célula anteapical externa triangular.

Pigóforo com um par de apêndices dorso-apicais, voltados para baixo. Estilos com apófise curta e digitiforme. Edeago tubular, curvo para cima; apêndices sinuosos, paralelos quase tão longos quanto o edeago.

Fêmea. Externamente semelhante ao macho. Sétimo esterno com a margem posterior sinuosa com leve projeção mediana.

Comprimento. Macho: 4,30. Fêmea: 4,90.

Material examinado. Holótipo macho. BrasiL, Mato Grosso: Cáceres, 14.I.1985, C. Elias leg. (DZUP). Parátipos. Ibidem, 14.XI.1984, C. Elias leg., 1 macho, 1 fêmea (DZUP).

Discussão. Externamente semelhante a $G$. clitellaria (Osborn) e G. guajarensis sp. nov. no padrão de coloração da face, escutelo e das tégminas porém o clavo não apresenta a veia extranumerária. O edeago é mais ou menos falciforme e os apêndices são tão longos quanto próprio edeago.

\section{Garapita (Chlamydopita) Linnavuori, 1959}

Garapita (Chlamydopita) Linnavuori, 1959: 225. Espécie-tipo, Garapita aurea Linnavuori, 1959: 225 (designação original).

Coloração amarelada com manchas fulvas e marrons. Tégminas com célula anteapical externa de lados paralelos. Pigóforo, do macho, sem apêndices. Estilos com apófise curta; ângulo pré-apical arredondado.

\section{Garapita (Chlamydopita) aurea Linnavuori, 1959 Figs 51-55}

Garapita (Chlamydopita) aurea Linnavuori, 1959: 225 (descrição). Zanol \& Menezes, 1982: 40 (citação).

Holótipo macho. Coroa amarela; margem anterior com quatro manchas marrons; região discal com duas faixas longitudinais fulvas. Face amarela.

Pronoto amarelo com quatro faixas longitudinais fulvas e duas marrons, estas nas laterais.

Tégminas amarelas com venação marrom; clavo margeado de branco; ápice do clavo marrom; células com manchas longitudinais marrons; ápice marrom. Célula anteapical externa retangular.

Pigóforo sem apêndices. Estilos com apófise digitiforme. Edeago lamelar; ápice com um processo espiniforme ventral, voltado para trás; apêndices basais sinuosos mais longos que o edeago.

Fêmea. " $7^{\text {th }}$ esternite sharp-triangularly produced medially. Pygofer long and narrow".

Comprimento. Macho: 4,50 .

Material examinado. BRASIL, Santa Catarina: Seara (Nova Teutônia), $27^{\circ} 11^{\prime} \mathrm{B} .52^{\circ} 23^{\prime} \mathrm{L}$. Fritz Plaumann leg. 18.12.1937. Typus Garapita aurea Lv (AMNH).

Discussão. Difere das demais espécies do gênero no padrão de coloração, por apresentar a célula anteapical externa retangular e pelos caracteres da genitália.

\section{REFERÊNCIAS BIBLIOGRÁFICAS}

LINNAVUORI, R. 1959. Revision of the Neotropical Deltocephalinae and some related subfamilies. Annales Zoologici Societatis Zoologicae Botanicae Fennicae "Vanamo", Helsinki, 20 (1): $1-370$.

OmAn, P.W. 1936. A generic revision of American Bythoscopinae and South Amarican Jassinae. University of Kansas Science Bulletin, Lawrence, 24 (16): 343-420.

Osborn, H. 1926. V. Neotropical Homoptera of the Carnegie Museum. Part 5. Report upon the collections in the subfamily Cicadellinae, with descriptions of new species. Annals of the Carnegie Museum, Pittsburgh, 16 (2): 155-248.

YounG, D.A. 1977. Taxonomic study of the Cicadellinae (Homoptera: Cicadellidae). Part 2. New world Cicadellini and genus Cicadella. The North Carolina Agricultural Experiment Station Technical Bulletin, Raleigh, 239: 11135.

Recebido em 25.XI.2002; aceito em 13.V.2003. 